\title{
Design of Fixture for Pitch Circle Diameter Run-out Check
}

\author{
Ganesh Patil*, Saurabh Patil and Rohit Patil
}

Department of Mechanical Engineering, Suman Ramesh Tulsiani Technical Campus, Faculty of Engineering, Khamshet, Pune 410405 (Maharashtra) India

Received 01 March 2018, Accepted 01 May 2018, Available online 06 May 2018, Vol.8, No.3 (May/June 2018)

\begin{abstract}
The design of fixture is an exceptionally mind boggling and natural process, which require learning and knowledge. Fixture configuration assumes an imperative part at the setup arranging stage. Appropriate fixture configuration is urgent for creating item quality in various terms of exactness, surface complete and accuracy of the machined parts. In existing plan the installation set up is done physically, so the point of this undertaking is to supplant with installation to spare time for stacking and emptying of segment. Apparatuses are ordinarily grouped by the kind of machine on which they are utilized. Installations can likewise be recognized by a sub arrangement. For instance, if an installation is intended to be utilized for examination called as inspection apparatus. By using the new designed fixture, run-out checking become easier and process becomes simpler.
\end{abstract}

Keywords: Fixture, Run-out, Pitch circle diameter, Manufacturing, Locator, Inspection, Gears

\section{Introduction}

The apparatus is an uncommon device for holding a work piece in legitimate position amid assembling activity. For supporting and clasping the work piece, gadget is given. Visit checking, situating, singular stamping and non-uniform quality in assembling process is wiped out by apparatus. This expansion efficiency and lessen activity time. Installation is generally utilized as a part of the business viable generation in view of highlight and points of interest. To find and immobilize workpieces for machining, review, gathering and different tasks apparatuses are utilized. An installation comprises of an arrangement of locators and cinches. Locators are utilized to decide the position and introduction of a workpiece, though braces apply clipping powers with the goal that the work piece is squeezed solidly against locator. Clipping must be fittingly arranged at the phase of machining installation plan.

An installation ought to be safely affixed to the table of the machine whereupon the work is to be finished. Despite the fact that to a great extent utilized on processing machines, apparatuses are likewise intended to hold the work for different activities on the greater part of the standard machine devices. Apparatuses shift in configuration in view of the utilization of moderately basic devices to costly or confounded gadgets. Apparatus rearranges metalworking tasks performed on uncommon gear.

*Corresponding author's ORCID ID: 0000-0002-5744-8266 DOI: https://doi.org/10.14741/ijcet/v.8.3.1
The present work manages the outline of Gear Fixtures for G380 and GB85 gearbox second speed and third speed gears. The assignment close by was to plan installation for the parts, to be specific Reduction perfect rigging and fourth and third speed intend for adapt confine utilized HMT Tractors. Installation plan and choice begins with the part and the assembling task to be performed. The criteria for this plan procedure are exactness, positive area, repeatability, generation rate and significantly, the dependability under the activity of the cutting power and shear experienced. The clipping powers and development effortlessness have additionally been represented outline. The proposed configuration was then checked for exactness under the activity of the included tasks. Master examiners at that point affirmed the outline.

Fixtures are device for holding work piece in proper location during manufacturing operation. To support and clamping the work piece, device is provided. Continuous checking, positioning, marking and non-uniform quality in manufacturing process is eliminated by fixture. It leads to increase productiveness and reduce operation time. Fixtures are widely used in the industry practical production because of lineament and advantages. To locate and block work pieces for machining, inspection, assembly and other operations fixtures are used. The old process was to take mandrel put the gear on it and after that put it in between tailstock and headstock. After setting it in between the PCD was been checked on dial gauge. The pointer is put between two dog teeth. This process was time consuming and hard for operator to work on 
it. The PCD of gears of diameter $50 \mathrm{~mm}, 65 \mathrm{~mm}$ was to be checked.

Fixture planning and design is defined in this context as consisting of all the tasks and information required to design a work holder to locate, hold, and support a workpiece during a machining process.

\section{Literature review}

N. P. Maniar et al. in his work in design \& development of fixture for CNC explained that fixture design is one of the most important design tasks during process design for a new product development since it involves defining the locations and orientations of parts during assembly processes as well as providing physical support, which can greatly affect product dimensional variations and process yield. Generally, fixture design process can be divided into three stages.

Fixture planning: In the fixture planning stage, issues related to the number of fixtures needed, the type of fixtures, the orientation of fixture corresponding to orientation, and the joining or machining operations, which fixtures have to handle are identified.

Fixture configuration: The fixture configuration stage determines the layout of a set of locators and clamps on a workpiece surface such that the workpiece is completely restrained.

Apparatus development: Finally, the installation development organize includes building apparatus segments and after that introducing them to help the workpiece. Specifically, for complex assemblies such as an automotive body, a ship hull, and an aircraft fuselage, fixture layout design, which falls under the domain of the fixture planning and fixture configuration stages, is a primary concern and it involves adjusting the design nominal of locator positions in order to eliminate mean shifts.

In the fixture planning phase, production requirements indicate batch sizes, types of machines, human resources, and the overall cost. Other requirements such as quality standards may dictate functional considerations such as inspection and tolerance specifications. Research in this area focus on production planning optimization techniques such as scheduling models and algorithms. In the design phase, where most of the documented research has been concentrated, there are two sub phases.

During the design phase, a detailed 'analysis' is examined to locate and position the workpiece. The next sub phase is 'synthesis'. This phase can also be referred to as 'fixture representation'. The determination of installation components is required to fulfill the prerequisites and speak to the apparatus design. There are essentially two ways to deal with get together, manual or computerized. Though this research may be investigated outside the realm of fixture design, the results can be implemented in this area. The scientific categorization of installation configuration arranges and sorts out apparatus configuration instruments and would fill in as a decent characterization for look into bearings.
It provides a visual arrangement of investigations in the fixture design area and provides a perspective in relation to other areas of research.

Fixture planning and design relies on the experience, skills, and knowledge of the tool designer. Though considered as an isolated activity, the tool designer requires information from preceding and succeeding functions in order to effectively locate and hold the workpiece for machining operations.

The fixture designing and experimentation is considered as complex process that demands the knowledge of different are- as, such as geometry, tolerances, dimensions, procedures and experimentation processes. While designing this review work, a good number of literature and titles written on the subject by renowned authors are referred.

Poonam D. Chavan et al. in her study of a study of ring gear runout checking fixture explained that fixtures are widely used in industries due to their quality of increasing the accuracy and minimizing the operational time. Examination in assembling incorporates estimating, looking at, testing, or checking at least one qualities of an item or process and contrasting the outcomes with indicated prerequisites with decide if is the requirements are met for each characteristic. Inspection fixtures are used to check the quality of the workpieces, parts and components of machines. This paper shows the arrangement as a unique reason 'Runout Checking Fixture', which can be valuable for checking the runout of a part up to the desired tolerance with increased precision. The component is starter ring gear which is fitted on the periphery of flywheel of internal combustion engine.

Installation is an uncommon reason device which is utilized to encourage creation (machining, gathering and investigation activities) when workpieces are to be delivered on a mass scale. The use of fixture eliminates frequent checking, individual marking, positioning and non-uniform quality in the manufacturing process. This increase productivity and reduce operating time. An inspection (qualifying, gauging) operation is any examination of a workpiece that determines whether or not it meets the standards of quality. Dimension inspection or gauging fixtures raise the efficiency of the work of human inspectors; improve their working conditions, quality of workpieces, parts and components of machines. Installations for checking parts are typically utilized at middle of the road phases of machining (well ordered investigation) and at the last phase of machining (acknowledgment assessment) to confirm the precision of measurements, relative position of surfaces and adequacy of surface geometry. During the design phase, a detailed 'analysis' is examined to locate and position the workpiece. The next sub phase is 'synthesis'. This phase can also be referred to as 'fixture representation'. The determination of installation components is required to fulfill the prerequisites and speak to the apparatus 
design. There are essentially two ways to deal with get together, manual or computerized. Though this research may be investigated outside the realm of fixture design, the results can be implemented in this area. While designing this review work, a good number of literature and titles written on the subject by renowned authors are referred.

Satyajeet sing Raijada et al. in his investigation of design of a fixture of connecting rod for boring operation explained that fixtures are normally classified by the type of machine on which they are used. Apparatuses can likewise be distinguished by a sub order. For instance, if an installation is intended to be utilized on a processing machine, it is known as a processing apparatus. On the off chance that the undertaking it is expected to perform is straddle processing, it is known as a straddle-processing apparatus. A similar rule applies to a machine apparatus that is intended to machine radii. It is known as a machine sweep apparatus.

\section{Apparatus Design Processes}

Setup arranging: Determine no of setups, determine the work piece introduction and positions, decide machining datum highlights and finding surface.

1. Fixture planning: Determine locating positions, determine clamping surface, Determine clamping positions.

2. Unit design: Generate a unit design.

3. Validation: Trial manufacturing based on modifications.

\section{Design}

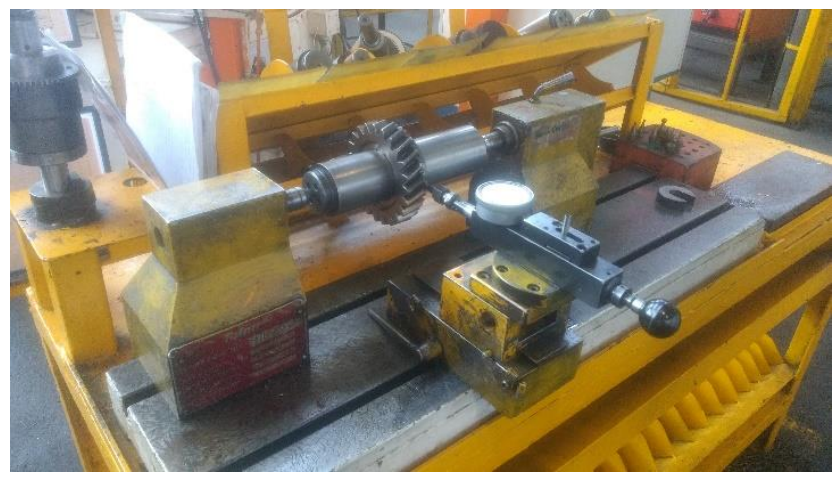

Fig.1 Old setup for PCD check

\section{Problem Statement}

The operation includes various steps such as:

1. Choose a mandrel according to bore diameter of gear which we are going to check.

2. Fix the gear in the mandrel

3. Hold the mandrel in between headstock and tailstock

4. Adjust the dial gauge fixture according to gear by sliding it on guide ways.
5. Set the gauge to zero reading.

6. Rotate the gear by rotating the mandrill and check the dial gauge reading deflection.

\section{Objectives}

a) To eliminate mandrel operation.

b) To reduce the space required for the fixture.

c) To eliminate time required for gear arrangement for checking.

d) To allow the rotation of gears on locator for checking the deflection in dial indicator at different points on pitch circle of gear.

e) To reduce the operator fatigue.

\section{Problem Formulation}

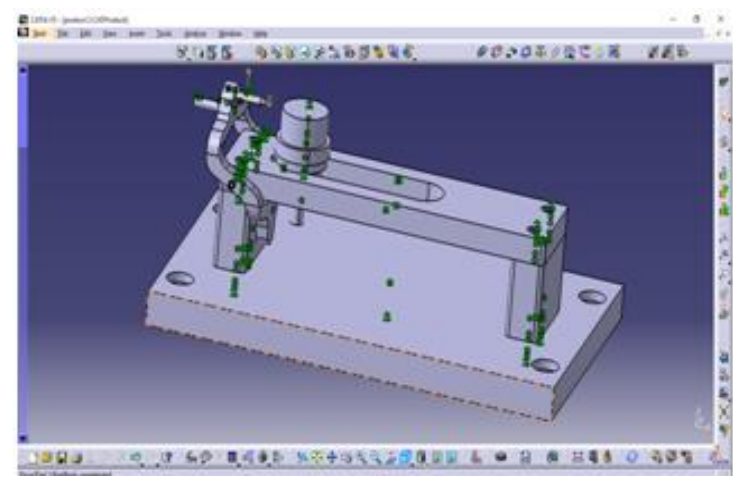

Fig.2 Catia model- Assembly of new fixture

a) The above [Fig 2] CAD diagram shows the new fixture designed

b) All the old fixture disadvantages are overcome in this new fixture

c) The main part for holding gears is Locators

d) The gears are put on the locator and the Pitch circle diameter run out checking are carried out

e) The below [Fig 3] CAD MODEL shows the locator base for diameter $55 \mathrm{~mm}$

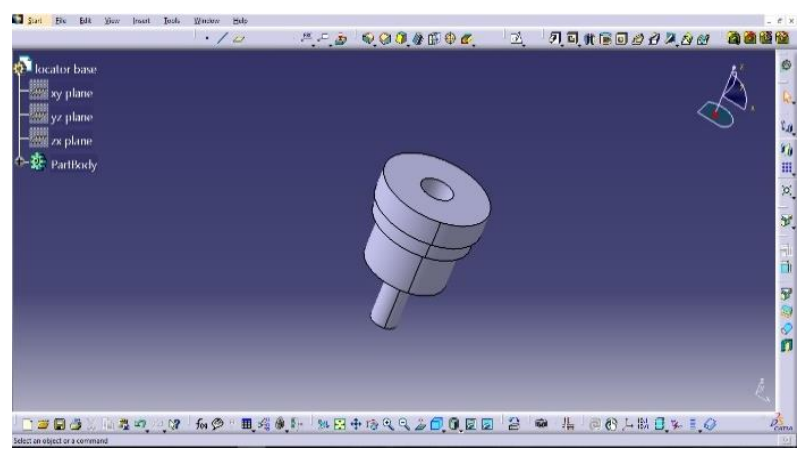

Fig.3 Locator base

On this locator base the locator is placed, on which the gear to be checked, is placed for checking, the above shown locator base which is provided by taping. 
The below [Fig 4] CAD diagram shows the bore diameter $55 \mathrm{~mm}$ locator which will be placed on the above locator base.

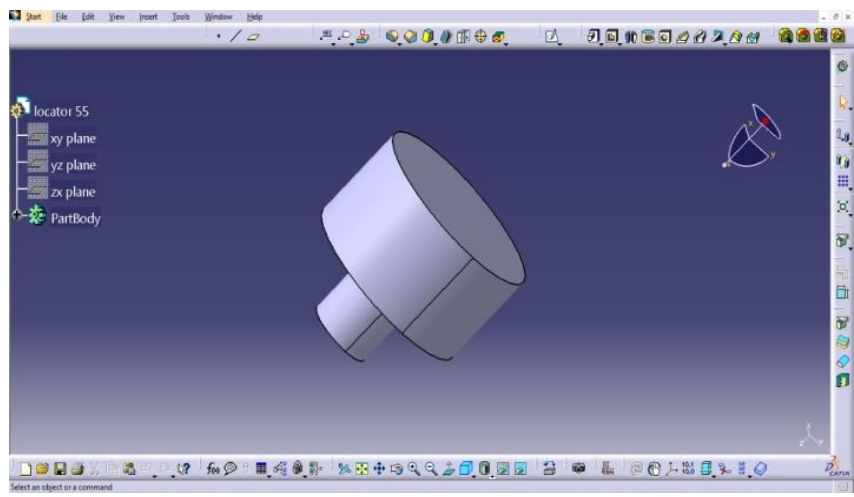

Fig.4 Locator

The new process operation includes various stages such as:

1. Take the fixture.

2. Take the locator base and put into the the gap shown in the new main fixture diagram.

3. After putting the locator base take the bore diameter locator which is provided by taping and fix it.

4. Now put the gear whose pitch circle diameter has to be checked.

5. By rotating the locator, the checking is carried out with the help of pointer.

6. While rotating simultaneously the reading on dial indicator in micron are taken.

7. The reading is achieved by the bend lever shown in the figure which has a spring connected to plunger of dial indicator.

8. This is how the operation is carried out on new fixture.

\section{Result}

\section{Actual manufactured fixture}

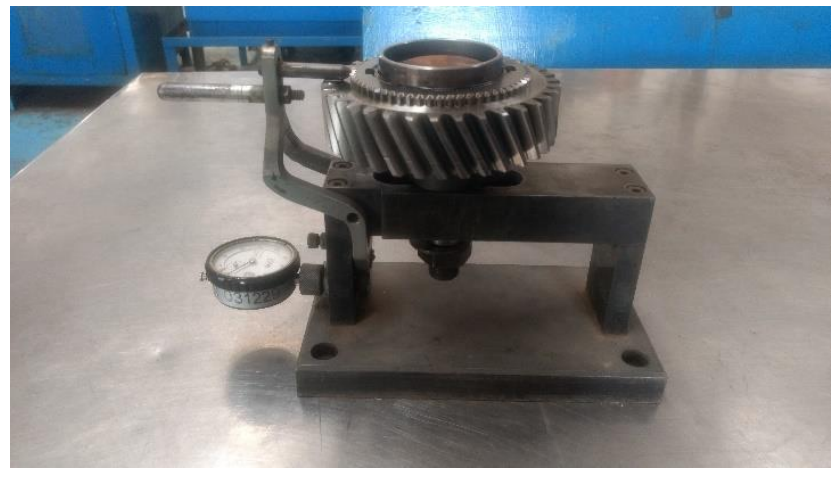

Fig.5 New manufactured fixture
Table 1 Experimental results

\begin{tabular}{|c|c|c|c|}
\hline Sr no & Parameters & Old process & New process \\
\hline 1 & Gears Checked & 200 & 400 \\
\hline 2 & $\begin{array}{c}\text { Range on Dial } \\
\text { Indicator }\end{array}$ & $0.35-0.40$ & $0.2-0.25$ \\
\hline 3 & Space Required & More & Less \\
\hline 4 & Operation & Tedious & $\begin{array}{c}\text { Simpler as } \\
\text { compared to } \\
\text { initial process }\end{array}$ \\
\hline 5 & Time & 1 min-4 gears & 1 min-7 gears \\
\hline
\end{tabular}

\section{Conclusion}

1. We have successfully designed and manufactured a fixture for pitch circle diameter checking.

2. After the testing of fixture, we have improved the inspection process. The time required for checking the gears is reduced.

3. In previous process there are only 4 gears were checked per minute but due to change in design the gear checking rate is improved to 7-8 gears per minute. Now approximately $85 \%$ - 90\% more gears are checked.

4. The number of gear checking is improved by approximately twice the previous process.

5. The space required for the fixture is reduced and material handling became easier.

6. The operator fatigue is reduced to minimum as mandrel fitting operation is eliminated.

7. We have removed all the disadvantages of previous fixture.

8. Hence efficiency of operation is improved.

\section{References}

N. P. Maniar, D. P. Vakharia (2013), Design \& Development of Fixture for CNC - Reviews, Practices \& Future Directions, International Journal for Scientific and Engineering Research, Vol-4, Issue 2.

Poonam D. Chavan, Komal M. Barge (2015), A Study of Ring Gear Run Out Checking Fixture, International Journal for Research in Applied Science \& Engineering Technology, Vol-3, Issue $\mathrm{V}$.

Satyajeet singh Raijada, Amit Dudhatra(2014), Design of a Fixture of Connecting Rod for Boring Operation, International Journal of Engineering Research and Development, Vol-2, Issue 09.

K.V.S. Seshendra Kumar (2012), Design of Gear Cutting Fixture for CNC Gear Hobbing Machine, International Journal of Engineering Research and Publication, Volume 2, Issue 9.

Mr. Sagar Kumar(2012), Design and Fabrication of Gear Cutting Attachment to Lathe for Machining A Spur Gear, International Journal for Innovation and Engineering, Vol-4.

Shivaji Mengawade, Vaibhav Bankar, Pratik P Chaphale(2016), A Review on Design and Analysis of Work Holding Fixture, International Journal of Engineering Research and General science, Volume 4, Issue 2. 